\title{
Evaluating the Usefulness of the Adapted Thematic Analysis in the Process of Design
}

\author{
Nela Brown \\ University of Greenwich \\ Old Royal Naval College \\ Park Row, London SE10 9LS \\ N.Brown@greenwich.ac.uk
}

\begin{abstract}
A number of $\mathrm{HCl}$ studies reported thematic analysis method as a useful tool for evaluating existing technologies and informing design of new technologies. Whilst these studies reported on the resulting designs, they lacked detailed account about the use of the method itself or how the output of the method was linked to proposed designs. To explore this 'knowledge gap', thematic analysis method was applied to a data set resulting from semi-structured interviews conducted with five families. The adaptation of the thematic analysis approach led to a new 'output' in which findings were structured into a Design Map consisting of Categories, Themes and Codes. The usefulness of this Design Map in the process of design was evaluated in a study conducted with participants studying design at an undergraduate level. This paper describes the rationale for using Lean UX approach to refine the aims of the study and reports results from the Exit Questionnaires aiming to elicit participants' opinions about the use of a Design Map in the process of design.
\end{abstract}

Thematic analysis. Adapting qualitative methods. Lean UX. Design Map. Design process. Questionnaires.

\section{INTRODUCTION}

Thematic analysis, drawn from different fields (Joffe and Yardley, 2004; Braun and Clarke, 2006; Boyatzis, 1998; Fereday, and Muir-Cochrane, 2006), has been reported as a useful data analysis method in recent $\mathrm{HCl}$ research. These reports lacked detailed explanations about the use of the method itself, or how it linked to resulting design solutions, so a decision was made to use new data, gathered through semi-structured interviews with families with primary school children (called 'Introductory Interviews'), and explore the method thematic further.

After different approaches to the method were examined, the 6-Phase approach outlined in Braun and Clarke (2006) was chosen. The first round of analysis resulted in a high-level thematic map accompanied by the analytic narrative, the outcome useful in $\mathrm{HCl}$ research where the aim is to present an overall summary of findings. The low-level design insights, useful for informing the design of new technologies or improving the functionality of existing technologies, were, however, completely lost in the analysis process. In the second round of analysis, the 6-Phase approach was adapted, resulting in the Introductory Interviews Design Map consisting of Categories, Themes and Codes, with the findings being structured in a way that provides a high-level overview, whilst also preserving lowlevel design detail. To explore the usefulness of the Introductory Interviews Design Map in the process of design, a study with undergraduate design students as participants was conducted.

\section{BACKGROUND}

\subsection{Exploring the TA 'knowledge gap'}

A number of $\mathrm{HCl}$ studies (Pykhtina et al., 2012; Money et al. 2008; Tanaka et al., 2012; Toth et al., 2012; Güldenpfennig, Reitberger and Fitzpatrick, 2012) reported thematic analysis method outlined in Joffe and Yardley (2004) and Braun and Clarke (2006), as being useful for evaluating existing technologies and informing design of new technologies. Whilst these studies reported on the resulting designs, they lacked detailed account about the use of the method or how the output of the method, a thematic map accompanied by data extracts embedded within the analytic narrative, besides making an argument in relation to the research questions, linked to the actual proposed designs. To explore this 'knowledge gap', the thematic analysis method outlined in Braun and Clarke (2006) was applied to a data set resulting from an exploratory study investigating family dynamics and the use of technology within families 
with primary school children. The data was gathered through semi-structured interviews with five families (called Introductory Interviews) and analysed following the 6-Phase approach outlined in Braun and Clarke (2006). Through this process, it was discovered that grouping themes into higherlevel categories in order to construct a thematic map (in Phase 4), was useful for representing a general overview in social science studies, though not as useful in the research where the aim was to gain insights into participants' behavior and the use of technology, so these insights can be used to improve functionality of existing technologies or inform design of new technologies (Brown and Stockman, 2013). The resulting thematic map was deemed too abstract to guide design decisions, whilst the analytic narrative, though underpinned with the data extract relevant to the research question, was lacking low-level detail necessary to drive design.

\subsection{Adapting TA and producing a Design Map}

Instead of producing a thematic map, at the end of Phase 4 of the analysis, a detailed account of the family dynamics and the use of technology within families with primary school children was initially structured into a 'thematic frame', containing a list of Themes captured across all five families. These Themes were further grouped into higher-level Categories forming a Design Map (fig.1). Each Category name in the Design Map was capitalized and highlighted in green font to enable it to stand out. The number of Themes each Category contained was listed in the bracket next to the Category name, with every Theme contained within that Category being listed underneath.

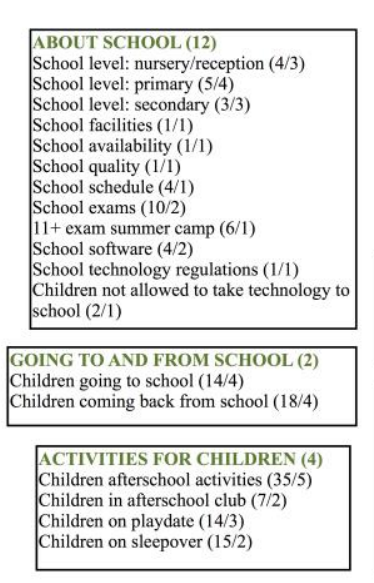

ACTIVITIES INVOLVING PARENTS \begin{tabular}{|l|}
\hline ACTIVITIES INVOLVING PARENTS \\
AND CHILDREN (5) \\
Family schedule (11/2) \\
Family weekly activities outside the home $(5 / 2)$ \\
Family weekly activities inside the home $(10 / 2)$ \\
Family weekend activities outside the home $(11 / 1)$ \\
Family weekend activities inside the home $(2 / 1)$
\end{tabular}

\begin{tabular}{|l|}
\hline CARING FOR CHILDREN (7) \\
Mom caring for children (15/4) \\
Dad caring for children (4/2) \\
Relatives caring for children (4/1) \\
Parents worry about children's safety (3/1) \\
Parents worry about children's happiness (2/1) \\
Parents want to protect children's privacy $(1 / 1)$ \\
Parents tracking (teenage) children (7/1)
\end{tabular}

Introductory Interviews Design Map

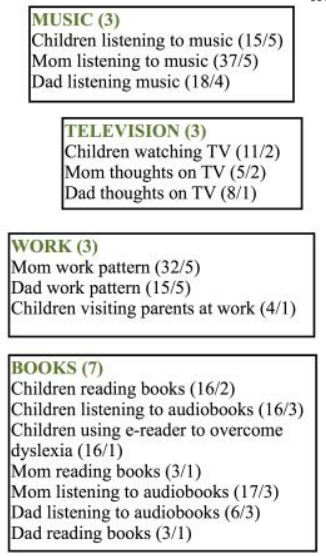

FAMILY MEMBERS APART (3) Parents apart from each other $(2 / 1)$ Parents apart from children $(12 / 4)$
Siblings apart from each other $(9 / 3)$

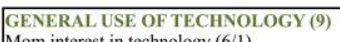
Mom interest in technology (6/1) Mom understanding technology $(2 / 1)$ Mom purchasing technology $(6 / 2)$ Dad interest in technology $(2 / 1)$ Dad purchasing technology $(3 / 1)$ Technology not working (5/2) Technology lacking feat
Cost of technology $(4 / 1)$ arents relying on each other for technology Parents relying
support (10/3)

\section{VIDEOS (5)}

Dad recording and playing back digital video $(7 / 2)$ Mom recording and playing back digital video $(6 / 2)$ Children recording digital videos (1/1) Mom recording and playing back analogue video (18/1)

\begin{tabular}{|c|}
\hline $\begin{array}{l}\text { ACTIVITIES INVOLVING RELATTIVES (2) } \\
\text { Parents contact with relatives (12/4) } \\
\text { Children contact with relatives }(11 / 4)\end{array}$ \\
\hline \begin{tabular}{|l|} 
USING LANDLINE PHONE $(3)$ \\
Mom using landline telephone $(25 / 2)$ \\
Dad using landline telephone $(2 / 1)$ \\
Children using landline telephone $(2 / 2)$
\end{tabular} \\
\hline $\begin{array}{l}\text { USING COMPUTERS (15) } \\
\text { Mom using computer (57/5) } \\
\text { Mom using email }(11 / 2) \\
\text { Mom using internet }(4 / 1) \\
\text { Mom downloading photos to computer }(9 / 3) \\
\text { Mom printing photos from computer }(15 / 1) \\
\text { Dad using computer ( }(21 / 5) \\
\text { Dad using email }(3 / 2) \\
\text { Dad using internet }(1 / 1) \\
\text { Dad downloading photos to computer ( }(7 / 2) \\
\text { Dad printing photos from computer }(4 / 2) \\
\text { Dad uploading photos to iPod nano }(1 / 1) \\
\text { Children using computer }(30 / 4) \\
\text { Childdren using email }(6 / 2) \\
\text { Children using internet }(22 / 1) \\
\text { Mom and children using internet together to learn } \\
\text { (7/1) }\end{array}$ \\
\hline
\end{tabular}

FAMILY COMMUNICATING VIA TECHNOLOGY (8) Daily communication between parents (11/4)

Communication between parents and children via landline and mobile (12/3) Communication between siblings via mobile and game console $(8 / 2)$ Children using walkie-talkies $(1 / 1)$

Mom using walkie-talkies $(6 / 1)$

Mom communicating with relatives via mobile $(2 / 1)$

Ded com

FAMILY SHARING PHOTOS (7)

Children sharing photos with parents via mobile and digital camera (3/2) Children sharing photos with friends via Mom mobile (4/1 Mom sharing photos with Dad via mobile (12/2) om sharing photos with friends via email and Facebook (5/1) om sharing photos with relatives via email, Facebook and MMS (7/2) Dad sharing photos with mom via
Dad showing photos to Mom $(5 / 1)$

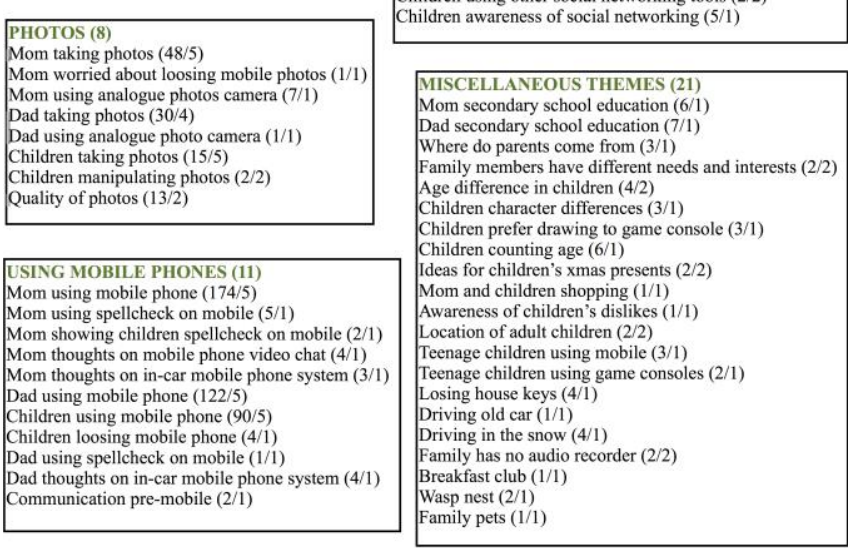

Figure 1: Introductory Interviews Design Map

The number of Codes contained within each of the Themes and a number of families talking about the Themes were added in a bracket next to the name of the Theme they were related to. Each Category was placed in a text box with a thin black border to enable visual separation between the categories and easier navigation through the Design Map. A list of Codes contained within the Themes was placed in a separate document, using the italic capitalised green font for the names of the Categories, bold black font for the names of the Themes and text indent before each of the listed Codes to enable easier visual navigation through the document. 


\section{THE STUDY}

\subsection{Recruiting participants}

29 participants (12 male and 17 female), from the Bachelor of Fine Arts (Hons) programme at the University of Malta, were recruited for the study. A lecturer from the programme, a native Maltese speaker, assisted with the study by providing insights into the tools and techniques the participants were taught (which led to some of these being incorporated into the study) and by offering bilingual clarification during the study.

\subsection{Using Lean UX approach to declare user assumptions and identify priorities for testing}

The study was driven by two hypotheses resulting from the adaptation of the thematic analysis approach: Solving Usability Issues, which proposed that "Having a list of low-level codes providing detailed insights into family members' behaviour involving existing technologies would enable researchers to identify usability issues and improve the design of these technologies" and Design Innovation, which proposed that "Having a list of low-level codes providing detailed insights into family members' behavior not involving existing technologies, would enable researchers to inform the design of novel technologies to support this behaviour".

The aim of the study was to investigate if the Introductory Interviews Design Map (the name of which was shortened to a 'Design Map' for the purpose of the study), could assist the participants with the completion of two tasks, related to those hypotheses, and elicit their opinions about the ways navigation through Categories, Themes and Codes could be improved. As hypotheses were too broad to test within the timeframe allocated per each group of participants (2 hours), the Lean UX approach (Gothelf and Seiden, 2013), previously explored in the context of software agency (Liikkanen et al., 2014) and learning (Dodero et al., 2014), was used to identify the parts of the hypotheses that were a priority to test.

First, a Business Assumptions Worksheet (Constable, 2015) was used to declare the following six User Assumptions:

(I) Who is the user of the Design Map?

(II) Where does the Design Map fit in the users' work?

(III) What problems does the Design Map solve?

(IV) When and how is the Design Map used?

(V) What features of the Design Map are important?

(VI) How should the Design Map look?
Then, the six Assumption Statements were created to answer these assumptions and a Prioritisation Matrix (Gothelf and Seiden, 2013, p.22), was used to determine the 'highest priority' assumptions to be tested (ii, iv and vi). Following this, three Hypothesis Statements: HSA2, HSA4 and HSA6, were created for each of these assumptions (Gothelf and Seiden, 2013). They each consisted of two parts, the first part outlining what is believed to be true for the Design Map and the second part outlining how this was going to be assessed. Hypotheses Statements HSA4 and HSA6 were still too broad, so had to be broken down into the following 'subhypotheses': HSA4sub1, HSA4sub2, HSA6sub1 and HSA6sub2.

\subsection{Designing tasks and questionnaires}

The study was designed in a form of two workshops, each consisting of two design tasks: 'Design Exercise 1' and 'Design Exercise 2'. The tasks included techniques the participants were already familiar with: 'Brainstorming', 'Random Input' (de Bono, 1970) and 'Six Thinking Hats' (de Bono, 1999) as well as a 'new tool', Design Map.

The aim of 'Design Exercise 1' was to explore if participants were able to use a Design Map to identify issues families with primary school children had with the use of technology. The aim of 'Design Exercise 2' was to explore if participants were able to identifying new possibilities for technology intervention for this demographic group. To evaluate the study, an Exit Questionnaire consisting of 18 question statements, grouped into the following four categories was designed:

(I) Questions aiming to find out about the workshop itself: the participants' understanding of the workshop purpose (Q1), the suitability of the workshop materials (Q13), the suitability of the level of the workshop (Q15), the participants' ability to complete the two tasks in a given time frame (Q14) and participants' comments about the ways workshop materials could be improved (Q18).

(II) Questions aiming to find out about the participants' current research process (Q16) and aiming to test Hypothesis Statement HSA2 to find out if Design Map could fit into their research process in the future (Q17).

(III) Questions aiming to test the two subhypotheses derived from Hypothesis Statement HSA6 (HSA6sub1, HSA6sub2) and evaluate participants' understanding of the relationship between the Categories, Themes and Codes (Q2, Q3), their ability to find the information quickly (Q4, Q5, Q6) and their own/ their team members' 
understanding of the Categories, Themes and Codes (Q7, Q8, Q9, Q10).

(IV) Questions aiming to test the two subhypotheses derived from Hypothesis Statement HSA4 (HSA4sub1, HSA4sub2), which formed the basis for the two tasks, and evaluate the participants' ability to identify usability issues (Q11) and possibilities for design innovation (Q12) within the workshop materials provided.

14 question statements used 5-point 'Level of Agreement' Likert-type scale with the verbal qualifiers: 'Strongly Agree - Agree - Neither Agree nor Disagree - Disagree - Strongly Disagree' (Vagias, 2006), frequently used in social sciences research (Rohrmann, 2007). One question statement used 5-point 'Level of Difficulty' Likerttype scale with the verbal qualifiers: 'Very Easy Easy - About Right - Hard - Very Hard'. Three questions were formulated as 'free text', allowing the participants to write their own comments by hand.

\subsection{Conducting the study}

Participants worked in teams of 4 or 5 , to complete design tasks using a Design Map (printed on one page), A0 sheets of paper, colored pens, highlighters, post-it notes and a document containing a 'breakdown' of the Design Map with the full list of Codes (printed on 33 pages). At the beginning of each of the workshops, participants were shown how to navigate through the Design Map's Categories, Themes and Codes.

\section{DISCUSSION OF RESULTS}

26 out of 29 participants completed the Exit Questionnaires (12 male and 14 female). In their responses to Q17 (related to User Assumption ii and HSA2), only one of the participants noted a Design Map could not assist them with their current way of working. One participant noted a Design Map would be useful if they were "designing a new product", whilst two participants noted it would be useful for academic work like "assignments \& projects" and "thesis".

The responses to questions Q11 and Q12 (related to User Assumption iv, HSA4sub1 and HSA4sub2), revealed that the majority felt they were able to identify usability issues $(84.62 \%)$ as well as possibilities for design innovation $(88.46 \%)$ using a Design Map.

The responses to questions Q2-10 (related to User Assumption vi, HSA6sub1 and HSA6sub2) further revealed that the majority also understood the relationship between Codes, Themes and Categories in the Design Map and the workshop materials $(84.62 \%)$; were able to find Categories, Codes $(73.08 \%)$ and Themes $(69.23 \%)$ they were interested in, understood the meaning of Themes $(84.62 \%)$ and Codes (73.08\%) and felt their team members had the same understanding of Themes $(73.08 \%)$ and Codes (73.08\%) as they did.

The responses to question Q16 ('What research tools and methods do you currently use to inform your design process?'), revealed a list of 22 different tools, techniques and strategies participants used to inform the design process, with 'Mind Maps' and 'Thinking Hats' being used by most.

\section{FUTURE WORK}

This study, testing User Assumptions ii, iv and vi with participants studying design at an undergraduate level (and as such, being relatively inexperienced as designers), confirmed the usability of a Design Map.

The responses in the Exit Questionnaires also confirmed that research findings structured in a way that provides a high-level overview (through Categories and Themes) whilst also preserving low-level design detail (through Codes), have a potential for being useful in the process of design.

As a follow up, a study comparing the two thematic analysis approaches, the 6-Phase approach (Braun and Clarke, 2006) and the adapted thematic analysis approach (Brown and Stockman, 2013), will be conducted with a new group of participants studying design at an undergraduate level, so that usefulness of both approaches, for improving the functionality of existing technologies or informing the design of new technologies, can be evaluated.

Some of the responses in the Exit Questionnaires indicated the need for adding more in-depth questions about participants' research and design background, as well as questions exploring the correlation between the participants' understanding of the workshop materials and the time spent working within the same team. This will be taken into account when designing future iterations of the Exit Questionnaire.

\section{ACKNOWLEDGMENTS}

This research was made possible thanks to EPSRC DTA grant; Chris Porter from the Faculty of ICT, Vince Briffa and Christine Porter-Lofaro from the Faculty of Media and Knowledge Sciences (MAKS) at the University of Malta, as well as all the undergraduate students who participated in this study. 


\section{REFERENCES}

Boyatzis, R.E. (1998) Transforming qualitative information: thematic analysis and code development. SAGE Publications, Inc.

Braun, V. and Clarke, V. (2006) Using thematic analysis in psychology. Qualitative Research in Psychology, 3 (2), 77-101.

Brown, N. and Stockman, T. (2013) Examining the Use of Thematic Analysis as a Tool for Informing Design of New Family Communication Technologies. Proceedings of the $\mathrm{BCS}-\mathrm{HCl}$ 2013, The $27^{\text {th }}$ International BCS Human Computer Interaction Conference: The Internet of Things. Uxbridge, UK, 9-13, September 2013.

Constable, G. (2015) Business assumptions exercise.

http://giffconstable.com/2011/12/businessassumptions-exercise/ (28 March 2018).

de Bono, E. (1999) Six Thinking Hats. Back Bay Books, NY.

de Bono, E. (1970) Lateral Thinking: Creativity Step by Step. Harper Colophon, NY.

Dodero, G. Melonio, A., Gennari, R. and Torello, S. (2014) Gamified co-design with cooperative learning. In Proceedings of $\mathrm{CHI}$ 2014, Toronto, Ontario, Canada, April 26-May 1 2014. ACM.

Fereday, J. and Muir-Cochrane, E. (2006) Demonstrating Rigor Using Thematic Analysis: A Hybrid Approach of Inductive and Deductive Coding and Theme Development. International Journal of Qualitative Methods (IJQM), 5(1). 8092.

Gothelf, J. and Seiden, J. (2013) Lean UX: Applying Lean Principles to Improve User Experience. The Lean Series. O'Reilly Media, Inc., 1005 Gravenstein Highway North, Sebastopol, CA.

Güldenpfennig, F., Reitberger, W. and Fitzpatrick, G. (2012) Of Unkempt Hair, Dirty Shirts and Smiling Faces: Capturing Behind the Mobile Camera. Proceedings of NordiCHI'12. Copenhagen, Denmark, 14-17 October 2012. 298-307.
Joffe, H. and Yardley, L. (2004) Content and thematic analysis, In Marks, D.F. and Yardley, L. (eds), Research Methods for Clinical and Health Psychology. London: Sage Publications. 56-67.

Money, A.G. et al. (2008) Older Adults' Experiences of Interacting with Online Forms. Workshop on $\mathrm{HCl}$ and the Older population. Proceedings of the BCS-HCl 2008, The 22nd British $\mathrm{HCl}$ Group Annual Conference on People and Computers XXII: Culture, Creativity, Interaction - Volume 2. Liverpool John Moores University, UK, 1-5 September 2008. 27-28.

Pykhtina, O. et al. (2012) Magic Land: The Design and Evaluation of an Interactive Tabletop Supporting Therapeutic Play with Children. Proceedings of the ACM Conference on Designing Interactive Systems (DIS). Newcastle, UK, 11-15 June 2012. 136-145.

Rohrmann, B. (2007) Verbal qualifiers for rating scales: Sociolinguistic considerations and psychometric data. Technical report, University of Melbourne, Australia.

Tanaka, A. et al. (2012) Survey and Thematic Analysis Approach as Input to the Design of Mobile Music GUls. Proceedings of the NIME'12. University of Michigan, Ann Arbour, USA, 21-23 May 2012.

Toth, N. et al. (2012) Teenagers Talking About Energy: Using Narrative Methods to Inform Design. Proceedings of the CHI '12, Austin, TX, USA, 5-10 May 2012. 2171-2176.

Vagias, W. M. (2006) Likert-type scale response anchors. Technical report, Clemson International Institute for Tourism \& Research Development, Department of Parks, Recreation and Tourism Management. Clemson University. https://www1.maine.gov/doe/arts/documents/like rt-typeresponseanchors2.pdf (28 March 2018).

Liikkanen, L. A., Kilpio, H., Svan, L. and Hiltunen, M. (2014) Leanux: the next generation of usercentered agile development? In NordiCHI'14. Proceedings of the 8th Nordic Conference on Human-Computer Interaction: Fun, Fast, Foundational, pages 1095-1100. New York, NY, USA, 2014. ACM. 